\title{
Author Correction: Human brown adipose tissue is phenocopied by classical brown adipose tissue in physiologically humanized mice
}

Jasper M. A. de Jong, Wenfei Sun (D), Nuno D. Pires, Andrea Frontini, Miroslav Balaz, Naja Z. Jespersen, Amir Feizi, Katarina Petrovic, Alexander W. Fischer (D), Muhammad Hamza Bokhari (D), Tarja Niemi, Pirjo Nuutila (D), Saverio Cinti, Søren Nielsen (D), Camilla Scheele (D), Kirsi Virtanen, Barbara Cannon, Jan Nedergaard, Christian Wolfrum and Natasa Petrovic (iD

Correction to: Nature Metabolism https://doi.org/10.1038/s42255-019-0101-4, published online 19 August 2019.

In the version of this article initially published, the percentages in the $x$ and $y$ axes in Fig. $6 \mathrm{~b}$ read $93 \%$ and 5\%, respectively, but should have read $72.5 \%$ and $11.0 \%$, respectively. The errors have been corrected in the HTML and PDF versions of the article.

Published online: 10 September 2019

https://doi.org/10.1038/s42255-019-0119-7 